Águas Subterrâneas (2014) 28(1): 95-104.

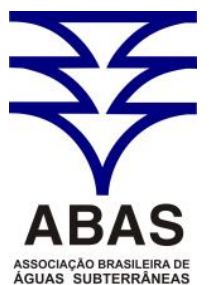

www.abas.org

\title{
REDES NEURAIS ARTIFICIAIS E ALGORITMOS EVOLUCIONÁRIOS MULTI-POPULAÇÃO NA OTIMIZAÇÃO MULTI-OBJETIVO DA REMEDIAÇÃO DE ÁGUAS SUBTERRÂNEAS
}

\author{
ARTIFICIAL NEURAL NETWORKS AND MULTI-POPULATION EVOLUTIONARY \\ ALGORITHM FOR MULTI-OBJECTIVE OPTIMIZATION OF GROUNDWATER \\ REMEDIATION
}

Marcos Rodrigues Pinto ${ }^{1}$, Camilo Allyson Simões de Farias², Eduardo Sávio Passos Rodrigues Martins ${ }^{3}$, Marco Aurélio Holanda de Castro ${ }^{4}$

Artigo recebido em: 16/01/2014 e aceito para publicação em: 30/04/2014.

\begin{abstract}
A groundwater remediation optimization problem through pump-and-treat technique is presented. Two objectives were pursued: 1) contaminant plume minimization; and 2) total cost minimization of remediation. Two multi-population evolutionary algorithms together with the artificial neural network (ANN) technology were employed in order to solve this problem. Pump rates from wells were sent to ANN that computes the remained contaminant mass left in the site. The ANN outcomes were sent to evolutionary algorithms to execute optimization process.
\end{abstract}

Keywords: Aquifer. Minimization. Contaminant plume. Cost.

Resumo: Apresenta-se um problema de otimização da remediação de águas subterrâneas por meio da técnica bombear-e-tratar. Dois objetivos são perseguidos: 1) minimizar a pluma contaminante; e 2) minimizar o custo total da remediação. A resolução desse problema é feita aplicando-se dois algoritmos evolucionários (AE) multipopulação juntamente com a tecnologia de redes neurais artificiais (RNA). As vazões dos poços são colhidas para a RNA, que calcula a massa restante de contaminante no sítio. As respostas dadas pela rede são avaliadas pelos algoritmos evolucionários a fim de efetuar a otimização.

Palavras-chave: Aquífero. Minimização. Pluma contaminante. Custo.

\section{INTRODUÇÃO}

A contaminação de águas subterrâneas apresenta prejuízos potenciais que vão desde os financeiros até o risco de morte de pessoas e animais. O comprometimento do solo para fins de agricultura, por exemplo, é um dos muitos prejuízos financeiros. Um dos mais graves acidentes envolvendo contaminação de águas subterrâneas é o de Bangladesh, do qual tomou-se conhecimento em 1993, sendo confirmado em 1995. Entre os países que evidenciaram contaminação por arsênio em larga escala estão Gana, Taiwan, norte da China, Hungria, Grécia, Áustria, México, Chile, Argentina e Estados Unidos (LIANA JOHN, 2003).
Por outro lado processos de remediação em geral requisitam custos altíssimos. Portanto, as técnicas de simulação/otimização da remediação apresenta-se como uma ferramenta imprescindível para tomadores de decisão na gestão de recursos hídricos. No intuito de se obter ferramentas apropriadas à resolução do problema de otimização de sistemas de bombeamento-e-tratamento muitos pesquisadores vêm aplicando diversas técnicas: redes artificiais neurais (ROGERS \& DOWLA, 1994); programação linear (AGUADO et al., 1974; MORGAN et al., 1993; BLANKS \& FLECK, 1999; AHLFELD et al., 1988; AHLFELD \& MULLIGAN, 2000); programação di-

\footnotetext{
1 Universidade de Fortaleza - UNIFOR; Doutorado em Recursos Hídricos POSDEHA-UFC - Professor do curso de engenharia ambiental e sanitária do Centro de Ciências Tecnológicas da Unifor, pesquisador do Labortário de Hidráulica Computacional (LAHC) do POSDEHA-UFC (mrp_marcos@yahoo.com.br).

2 Universidade Federal de Campina Grande - Professor Adjunto, Unidade Acadêmica de Ciências e Tecnologia Ambiental (camilo@ccta.ufcg.edu.br).

${ }^{3}$ Instituto de Ciências do Mar - Universidade Federal do Ceará; Fundação Cearense de Meteorologia e Recursos Hídricos-FUNCEME (esprm@gmail.com).

${ }^{4}$ Universidade Federal do Ceará - Vice-diretor do Centro de Ciência e Tecnologia da Universidade Federal do Ceará (marco@ufc.br).
} 
nâmica diferencial com restrição (CHANG \& HSIO, 2002); programação não-linear (MCkINNEY \& LIN, 1995; GORELICK et al., 1984); programação quadrática (LEFKOFF and GORELICK, 1986); hibridação simulada (DOUGHERTY \& MARRYOTT, 1991); plano de corte (KARATZAS and PINDER, 1996); algoritmos genéticos (ERICKSON et al., 2002; GUAN \& ARAL, 1999; ESPINOZA, 2003; PARK \& ARAL, 2004; SINHA \& MINSKER, 2007). Rao e Jamieson (1997), e.g., treinaram uma RDA utilizando modeladores de fluxo e de transporte para predizer os resultados das diversas combinações de taxas de bombeamento em poços de extração e de injeção, a qual foi aplicada juntamente com um algoritmo genético mono-obejetivo para resolver um problema de remediação de águas subterrâneas.

O processo de otimização na remediação de águas subterrâneas é geralmente um problema não-linear e não-convexo, o que sugere o emprego de métodos evolucionários como opção robusta e confiável. Além do mais, surgem naturalmente dois problemas conflitantes: o custo da remediação e o nível de limpeza do sítio. Isto significa que não é possível melhorar um dos objetivos sem piorar o outro. Portanto, o ponto crucial da otimização bi-objetivo é a obtenção da curva de troca entre esses dois tipos de objetivos (TOKOS et al., 2013).

Para proceder à otimização, há a possibilidade de acoplar ao AE os modeladores de fluxo de águas subterrâneas MODFLOW (MCDONAL \& HARBAUGH, 1988) juntamente com o de transporte multiespécies MT3DMS (ZHENG, 1990). Sem embargo, isso tornaria o custo computacional consideravelmente alto. Para evitar esse inconveniente, uma RNA foi treinada a partir das simulações feitas pelo MODFLOW e pelo MT3DMS, de modo a obter a massa restante de contaminante quando variávamos a taxa de bombeamento dos poços.

\section{METODOLOGIA}

\section{Algoritmos Evolucionários}

Os modelos históricos da Computação Evolucionária são quatro: Programação Evolucionária (FOGEL et al., 1966), Estratégias Evolucionárias (RECHEUBERG, 1973), Algoritmos Genéticos (HOLLAND, 1975) e Programação Genética (KOZA, 1992). Segundo Sivanandam e Deepa (2008), a diferença entre esses métodos reside na natureza dos esquemas de representação, nos operadores de reprodução e nos métodos de seleção.

Os AE são baseados nos processos adaptativos dos seres vivos: comportamento social, isto é, a forma de interagir entre os indivíduos de uma espécie; e luta pela sobrevivência, ligada ao ambiente externo de maneira geral. As relações entre indivíduos de dada espécie, e entre estes e seu habitat são traduzidas para uma linguagem algorítmica, no intuito de obter soluções ótimas para problemas do mundo real. A inspiração nos processos dos seres vivos faz sentido desde que a natureza tende a otimizar seus processos. Uma gota de chuva, e.g.; tende a assumir a forma de uma superfície mínima (de curvatura média igual a zero), a saber, a forma de uma esfera e, daí, irá sofrer menos ação das forças de resistência, caindo o mais rápido possível.

\section{Redes Neurais Artificiais}

O modelo constitui-se em uma RNA do tipo alimentada adiante feedforward, treinada pelo algoritmo de retro-propagação de erro (HAYKIN, 1999), modelo utilizado como base para obter a massa restante de contaminante ao variar-se as taxas de bombeamento dos poços. A implementação da RNA foi elaborada por meio da plataforma MATLAB $\odot$.

A arquitetura da RNA tem a seguinte formatação: uma camada de entrada, uma oculta (ou intermediária) e uma camada de saída. A de entrada possui dois neurônios, representando as taxas diárias de bombeamento nos dois poços $Q_{1}(t)$ e $Q_{2}(t)$. Na camada oculta, o número de neurônios foi determinado por um processo baseado em tentativa-e-erro, sendo os melhores resultados obtidos com dois neurônios na camada intermediária. O único neurônio da camada de saída representa o valor da porcentagem de contaminante restante $R E(t)$.

Foi escolhida a topologia da rede do tipo alimentada adiante, i.e.; as conexões ocorrem a partir da camada de entrada para a camada oculta, e da camada oculta para a camada de saída. A Figura 1 ilustra a topologia do modelo da RNA.

Para relacionar as entradas com as saídas da RNA, é preciso funções diferenciáveis e contínuas. A função sigmóide é uma boa função de ativação para cada neurônio porque seu comportamento é geralmente aceitável (HAYKIN, 1999). Para os neurônios da camada oculta, funções sigmóides foram usadas, enquanto no neurônio de saída uma função linear foi utilizada. 


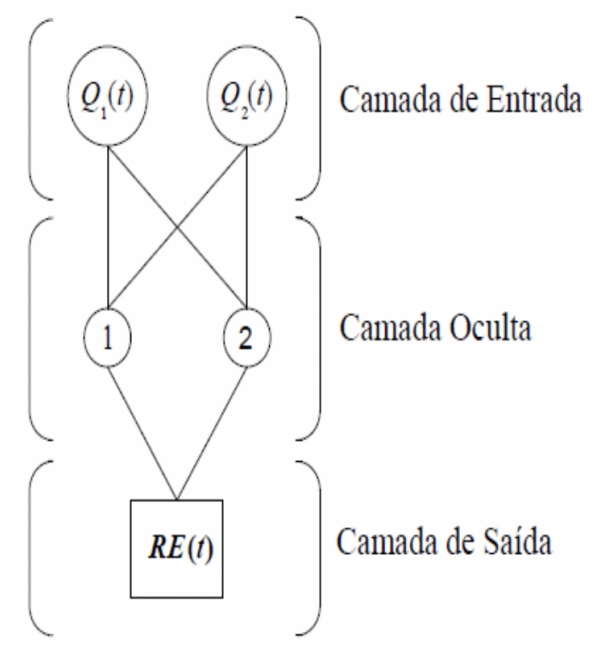

Figura 1 - Topologia da RNA

Figure 1 - ANN Topology

Escolheu-se para a calibração da RNA o algoritmo de retro-propagação de erro, com o qual já se obteve sucesso em diversos campos da engenharia. O algoritmo Levenberg-Marquardt (LM) foi empregado para retro-propagação. Hagan e Menhaj (1994) fornecem uma explicação detalhada do algoritmo LM. A calibração da RNA é do tipo supervisionado - os pesos sinápticos e níveis de bias entre os neurônios são ajustados por meio das iterações (ou épocas) com o intuito de adequar uma série de dados de entrada a outra série de respostas conhecidas. A calibração da RNA é encerrada pelo processo conhecido como "early stopping method" (DEMUTH e BEALE, 2005). Nele, os dados de calibração são divididos em dois subconjuntos, a saber, um de treinamento e outro de validação. $\mathrm{O}$ de treinamento é utilizado para calcular gradientes e ajustar os pesos e níveis de bias. Já o de validação tem seus erros monitorados objetivando evitar "overfitting" dos dados $\mathrm{e}$, conseqüentemente, melhorar o grau de generalização da RNA. A parada calibração ocorre quando o erro no subconjunto de validação cresce por um certo número de iterações.

\section{Esquema da Otimização}

Considera-se um sítio hipotético com 300 $\mathrm{m}$ de largura e $450 \mathrm{~m}$ de comprimento. A profundidade do aquífero é de $10 \mathrm{~m}$ e um fluxo constante é estabelecido em suas fronteiras leste e oeste, além de assumir-se a homogeneidade e a isotropia para esse aquífero. A fonte de contaminante ativa sobre o sítio permanece por 365 dias, atingindo certa massa inicial MI. Dada a desativação da fonte de contaminação, segue-se o processo de remediação. Um esboço da vista plana do aquífero com dois poços de extração e a fonte de contaminante é mostrado na Figura 2.

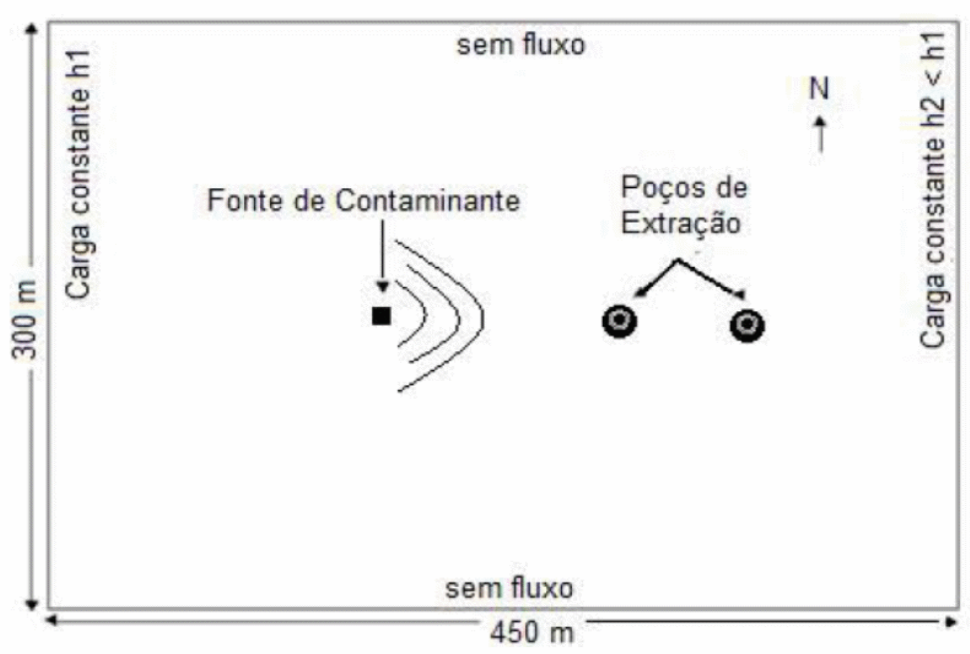

Figura 2 - Vista plana do sítio hipotético com a fonte de contaminante e dois poços de extração Figure 2 - Flat view of hypothetical site with contaminant source and two extraction wells

A fonte de contaminante dista $150 \mathrm{~m}$ da borda leste e da borda norte do aquífero. A $130 \mathrm{~m}$ da fonte, loca-se o poço 1, enquanto que o segundo poço é locado de forma a ser colinear com a fonte e o primeiro poço, $50 \mathrm{~m}$ distante do primeiro. No Quadro 1 encontram-se os demais parâmetros assumidos para o aquífero. 
Quadro 1 - Parâmetros do aquífero hipotético

Square 1 - Hypothetical aquifer parameters

\begin{tabular}{|l|r|l|r|}
\hline Porosidade & 0.3 & Dispersividade Longitudinal & $10 \mathrm{~m}$ \\
\hline Condutividade Hidráulica & $45 \mathrm{~m} /$ dia & Dispersividade Transversal & $3 \mathrm{~m}$ \\
\hline Comprimento & $450 \mathrm{~m}$ & Largura & $300 \mathrm{~m}$ \\
\hline
\end{tabular}

Em cada poço, a taxa de bombeamento máxima é de $250 \mathrm{~m}^{3} /$ dia. Uma restrição adicional a fim de garantir a maior influência de um poço no outro é a de que a diferença entre as taxas de bombeamento não seja superior a $15 \mathrm{~m}^{3} /$ dia.

Para simular o fluxo de água e o transporte de contaminante no aquífero, empregaram-se o modelador de fluxo de água subterrânea MODFLOW (MCDONALD e HARBAUGH, 1988) e o modelador de transporte MT3DMS (ZHENG, 1990), respectivamente. A grade de diferençafinita representando o aquífero consiste em blocos de $10 \mathrm{~m}^{2}, 31$ linhas e 46 colunas. Considerou-se que os poços penetram toda a espessura do aquífe- ro confinado de camada única. A elevação do topo e da base da camada é fixada em 10 e 0 , nesta ordem. Modelou-se a fonte de contaminante como um poço de injeção com taxa de $1 \mathrm{~m}^{3} / \mathrm{dia}$, sendo a concentração da água injetada de $1000 \mathrm{ppm}$. As figuras 3-a, 3-b, 3-c e 3-d, ilustram o processo em uma a vista plana do aquífero com a fonte de contaminante simulando do transporte nos tempos (a) 0 dias, (b) 146 dias, (c) 292 dias e (d) 365 dias. As linhas escuras indicam as fronteiras de carga constante e o quadrado representa a fonte do contaminante. A pluma contaminante tende a seguir na direção do fluxo, como pode ser visto nas figuras.

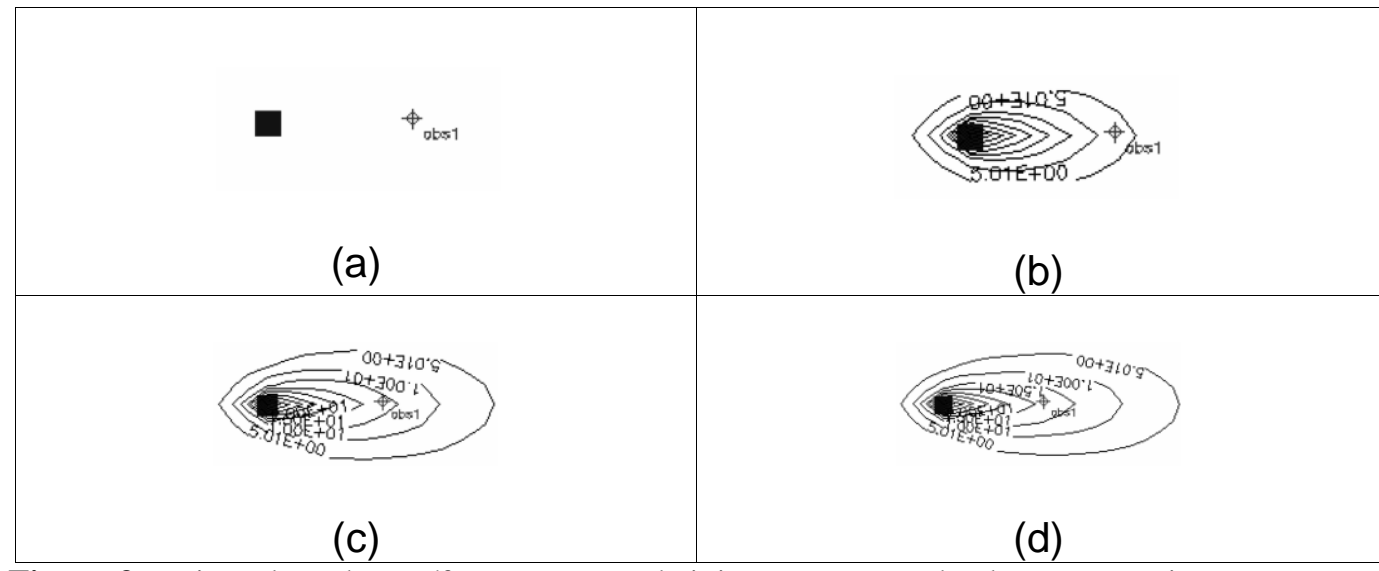

Figura 3 - Vista plana do aquífero com poço de injeção e avanço da pluma contaminante nos tempos (a) 0 dias, (b) 146 dias, (c) 292 dias e (d) 365 dias

Figure 3 - Flat view of aquifer with injection well and contaminant plume advance on (a) 0 day (b) 146 days (c) 292 days and (d ) 365 days

A equação 1 é aplicada para calcular a massa restante relativa (RE) a partir da massa restante (MR) e da massa inicial (MI).

$$
R E=\frac{M R}{M I}
$$

A equação 2 dá o custo total (CT), que considera os seguintes parâmetros: $a_{1}$, o capital por cada poço; $a_{2}$, o coeficiente de potência de bombeamento; $\mathrm{a}_{3}$, o coeficiente de custo de tratamento. Para este exemplo, a é igual a \$ $10.800,00 ; a_{2}$ é igual a 1,$05 ;$ e a $a_{3}$ é igual a 2,14.

$C T=2 \mathrm{a}_{1}+a_{2}\left(Q_{1}+Q_{2}\right)+a_{3}\left(C_{1}+C_{2}\right)$
As taxas de bombeamento nos poços 1 e 2 são representadas respectivamente por $\mathrm{Q}_{1}$ e $\mathrm{Q}_{2}$; enquanto $C_{1}$ representa a concentração de massa extraída no poço 1 , e $\mathrm{C}_{2}$, no poço 2 .

Ao ativarem-se os poços de bombeamento, MR varia com a taxa de bombeamento dos poços durante 365 . O comportamento da pluma pode ser visto nas figuras 4-a (0 dias), 4-b (73 dias), 4-c (292 dias) e 4-d (365 dias). Os quadrados opostos à fonte de contaminante representam os poços de extração. Note-se que as linhas equipotenciais mostradas são apenas linhas referentes aos respectivos dias, no intuito de faclitar a obser- 
vação do movimento da pluma. Adicionalmente, as distâncias entre as linhas equipotenciais foram configuradas no modo de apresentação do softwa- re Processing Modflow (c) a fim de melhorar a visualização da figura.

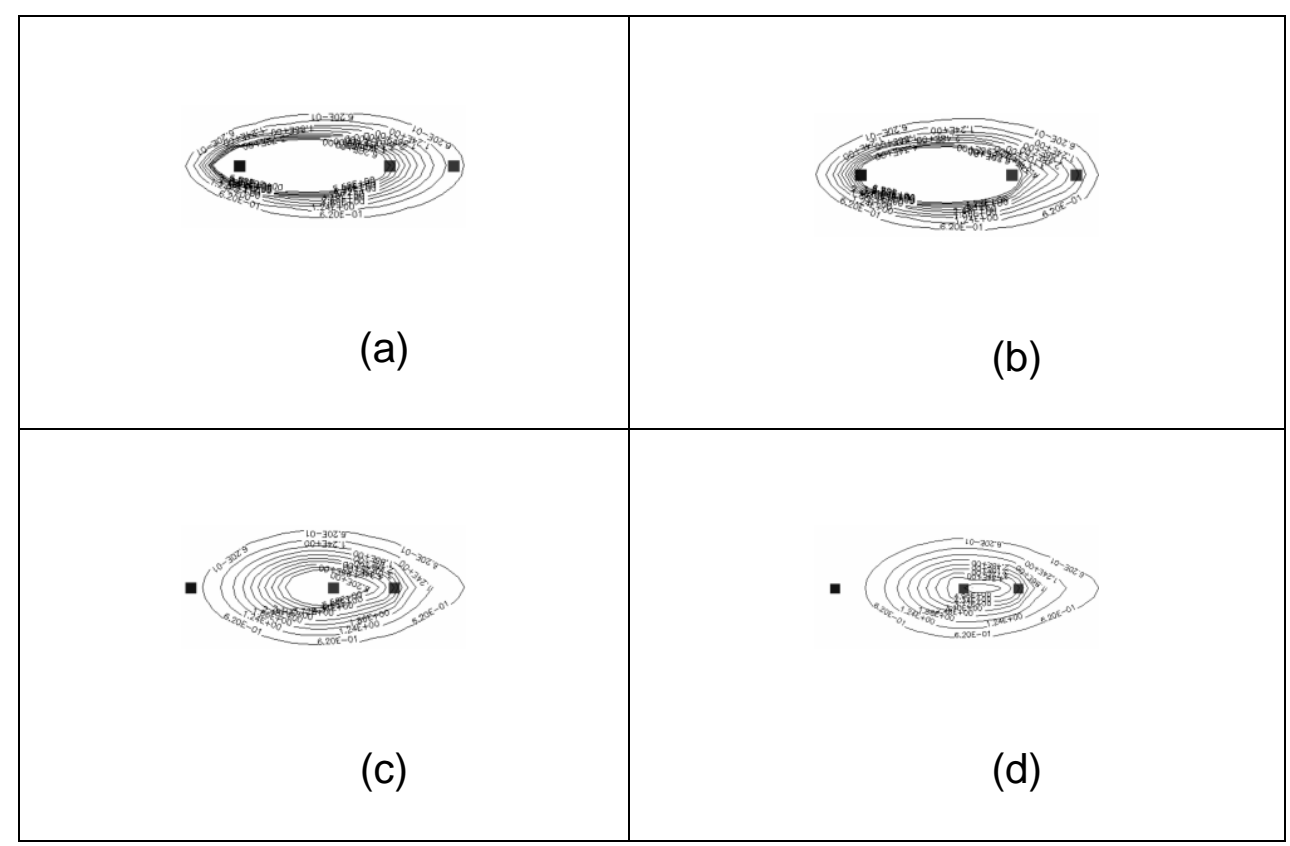

Figura 4 - Avanço da pluma em direção aos poços de extração no cenário 2. (a) 0 dias, (b) 73 dias, (c) 292 dias e (d) 365 dias

Figure 4 - Plume advance toward extraction wells in scenario 2. (a) 0 day, (b) 73 days, (c) 292 days and (d) 365 days

Utilizou-se uma RNA para simular as saídas dos modeladores MODFLOW e MT3DMS e gerar uma equação explícita, que é utilizada como função objetivo dentro do AE. A alternativa de acoplagem do MODFLOW e do MT3DMS diretamente no algoritmo foi preterida a fim de se reduzir o custo computacional da aplicação. A figura 5 apresenta o esquema.
Os benefícios do uso de RNAs como simuladores já foi demonstrado no artigo de Neelakantan e Pundarikanthan (1999), que utilizaram o modelo para simular o balanço hídrico de um sistema de reservatórios de forma a reduzir o tempo de processamento computacional para obtenção de regras ótimas de operação de reservatórios.

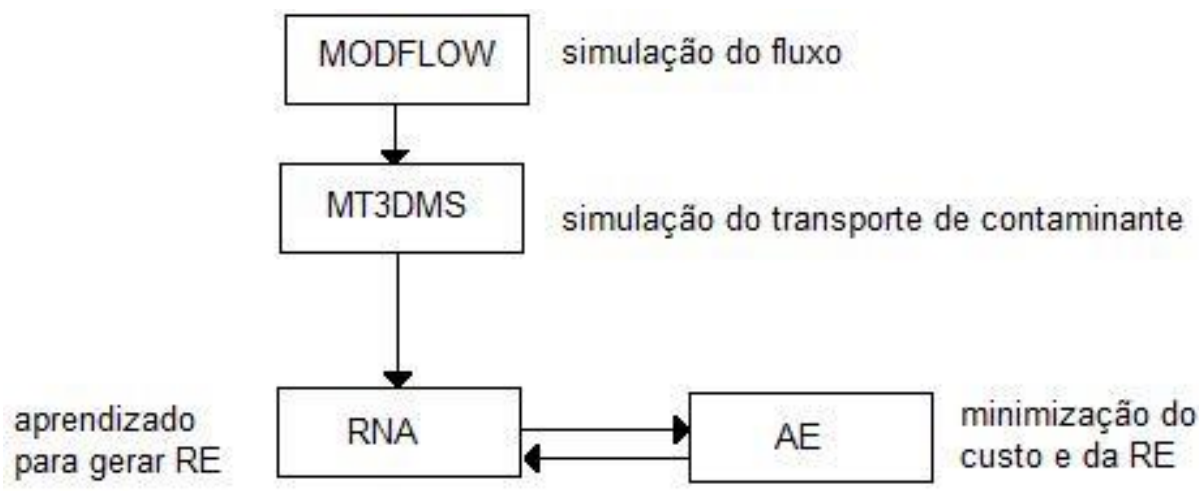

Figura 5 - Esquema de funcionamento do sistema de otimização

Figure 5 - Sketch of optimization system working

\section{RESULTADOS}

Para calibração da RNA foi usado um conjunto de dados constituído de 100 observações. Os dados foram divididos em duas metades, uma delas sendo utilizada para o treinamento da rede e, a outra, para validação. Como critério para avaliação do desempenho da RNA utilizaram-se 
os índices de correlação $(R)$ e bias $(B)$. A correlação é responsável pelo cômputo da variabilidade de um certo número de estimativas em torno do valor real, enquanto o bias fornece um grau para o qual dada estimativa é consistentemente maior ou menor do que o valor verdadeiro. Um ajuste per- feito entre valores observados e estimados teria $R=1$ e $B=0$. Latternmaier e Wood (1993) fornece equações para o cálculo desses índices. Um comparativo entre os resultados da RNA e os valores observados é apresentado na Figura 6.

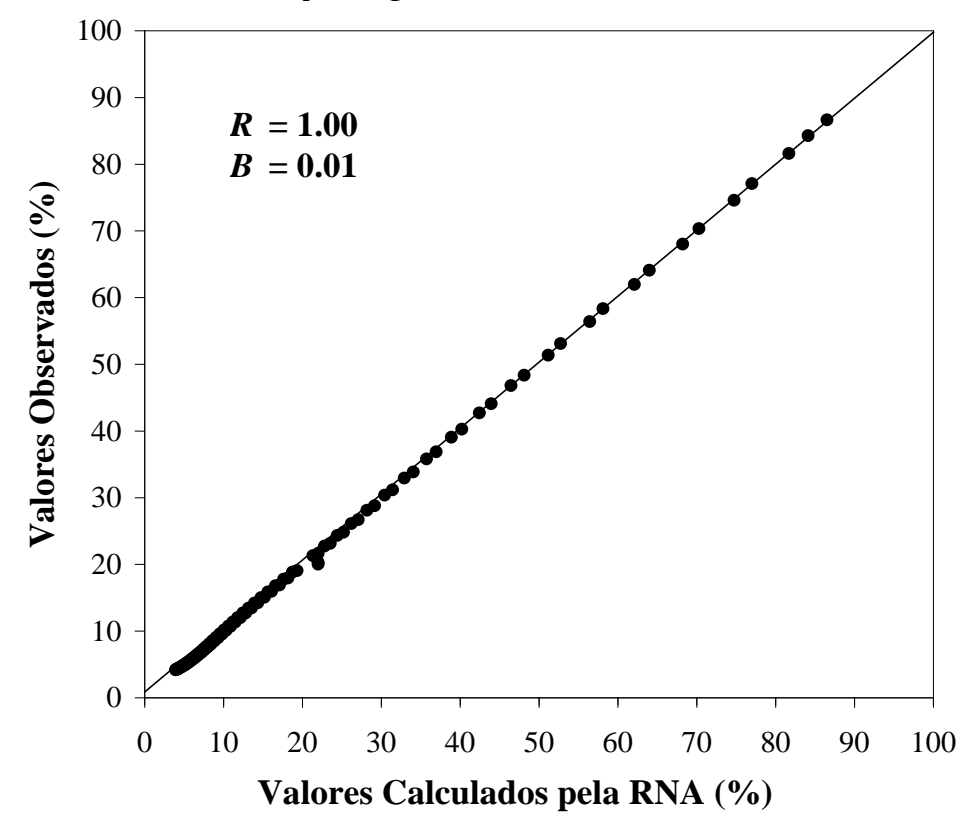

Figura 6 - Comparativo entre os resultados da RNA e os dados observados Figure 6 - Comparison of ANN results and observed data

Observando a Figura 6, pode-se concluir que a RNA apresentou resultados altamente confiáveis. Isto mostra o quanto as RNAs são interessantes quando se trata de estabelecer modelos não-lineares e para o ajuste de funções.

O gráfico da função ajustada pela RNA, que relaciona vazões com porcentagem de contaminante retido, pode ser visto na Figura 7.

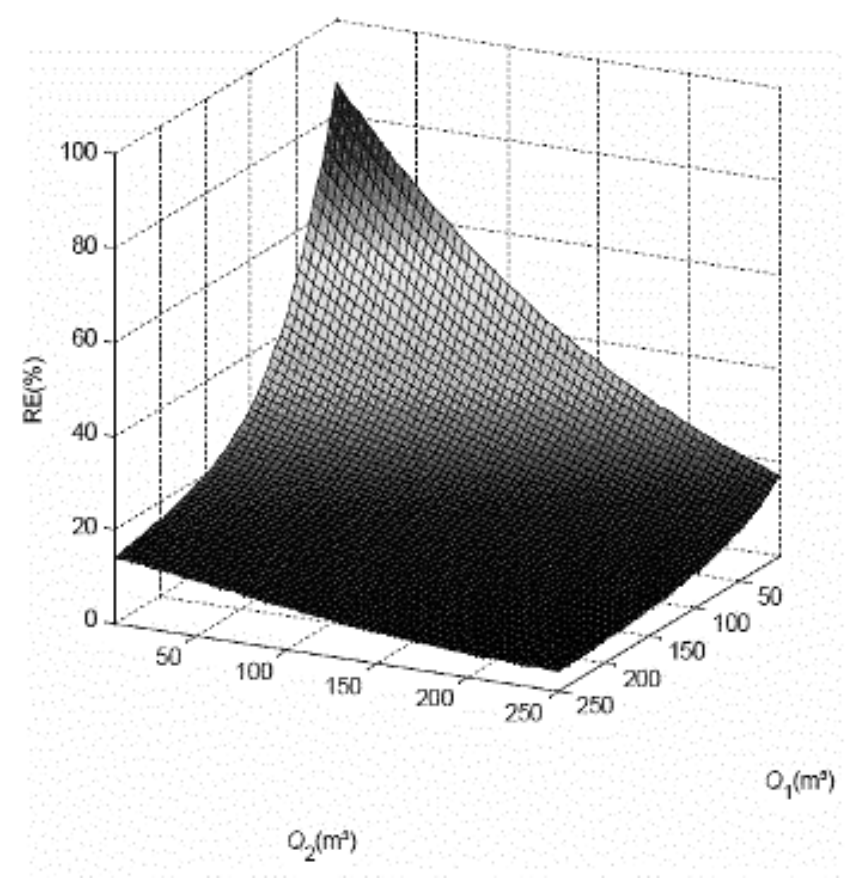

Figura 7 - Gráfico da função ajustada pela RNA

Figure 7 - Graph of function adjusted by ANN 
$\mathrm{O}$ algoritmo MINPGA - Multiple Island Niched Pareto Genetic Algorithm - (PINNTO, 2009) foi aplicado ao problema de otimização descrito na seção anterior. Esse algoritmo utiliza um raio denominado ninho de Pareto para resolver situações de conflito entre soluções com o mesmo ranking, considerando a distância entre as soluções conflitantes para determinação do raio (PINTO, 2009). O outro algoritmo é o sugerido por Niu et al. (2006), MCPSO (Multi-Cooperative Particle Swarm Optimization). A abordagem multipopulação é utilizada por ambos os algoritmos. Os quadros 2 e 3 apresentam os parâmetros utilizados no MCPSO e do MINPGA, respectivamente.
As figuras 8 e 9 apresentam as soluções para $R E$ versus $C T$ encontradas pelo MCPSO e MINPGA, nesta ordem.

De acordo com o explicitado pelas figuras 8 e 9, o número de soluções geradas pelo MINPGA é maior do que pelo MCPSO. O nível de remoção do contaminante encontrado utilizando o MCPSO varia entre $4 \%$ e $15 \%$; enquanto que, utilizando o MINPGA, obtêm-se soluções com níveis de limpeza de $4 \%$ até $94 \%$. Entretanto, isso não significa necessariamente que o MINPGA seja superior ao MCPSO, pois a natureza estocástica desses métodos introduz algumas variabilidades na resposta provida pelos algoritmos (CARRANO et al., 2011).

Quadro 2 - Parâmetros específicos do MCPSO

Square 2 - MCPSO specific parameters

\begin{tabular}{|l|r|l|l|}
\hline Parâmetro & Valor & Parâmetro & Valor \\
\hline Constante de aceleração & 0.8 & $\begin{array}{l}\text { Coeficiente de confiança no } \\
\text { grupo }\end{array}$ & 1.9 \\
\hline Fator de inércia & 0.7 & Velocidade máxima & $(0,1, \ldots ; 0,1)$ \\
\hline $\begin{array}{l}\text { Coeficiente de } \\
\text { autoconfiança }\end{array}$ & 2.1 & Número de Grupos-Mestre & 1 \\
\hline Número de voos & 100 & Número de Grupos-Escravo & 3 \\
\hline
\end{tabular}

Quadro 3 - Parâmetros do MINPGA utilizados em problemas bi-objetivos

Square 3 - MINPGA parameters for bi-objective problems

\begin{tabular}{|l|l|l|l|}
\hline Número de Populações & 3 & Raio de nicho & $*$ \\
\hline $\begin{array}{l}\text { Número de soluções iniciais por } \\
\text { população }\end{array}$ & 80 & $\begin{array}{l}\text { Tamanho do torneio de } \\
\text { seleção }\end{array}$ & 2 \\
\hline Probabilidade de cruzamento & 0.9 & Probabilidade de mutação & 0.001 \\
\hline Tipo de cruzamento e mutação & aritmético & Inicialização da população & Aleatória \\
\hline Trocas entre as ilhas por geração & 1 & Peso da solução & via Aptidão \\
\hline
\end{tabular}

* variando com a posição das soluções conflitantes 


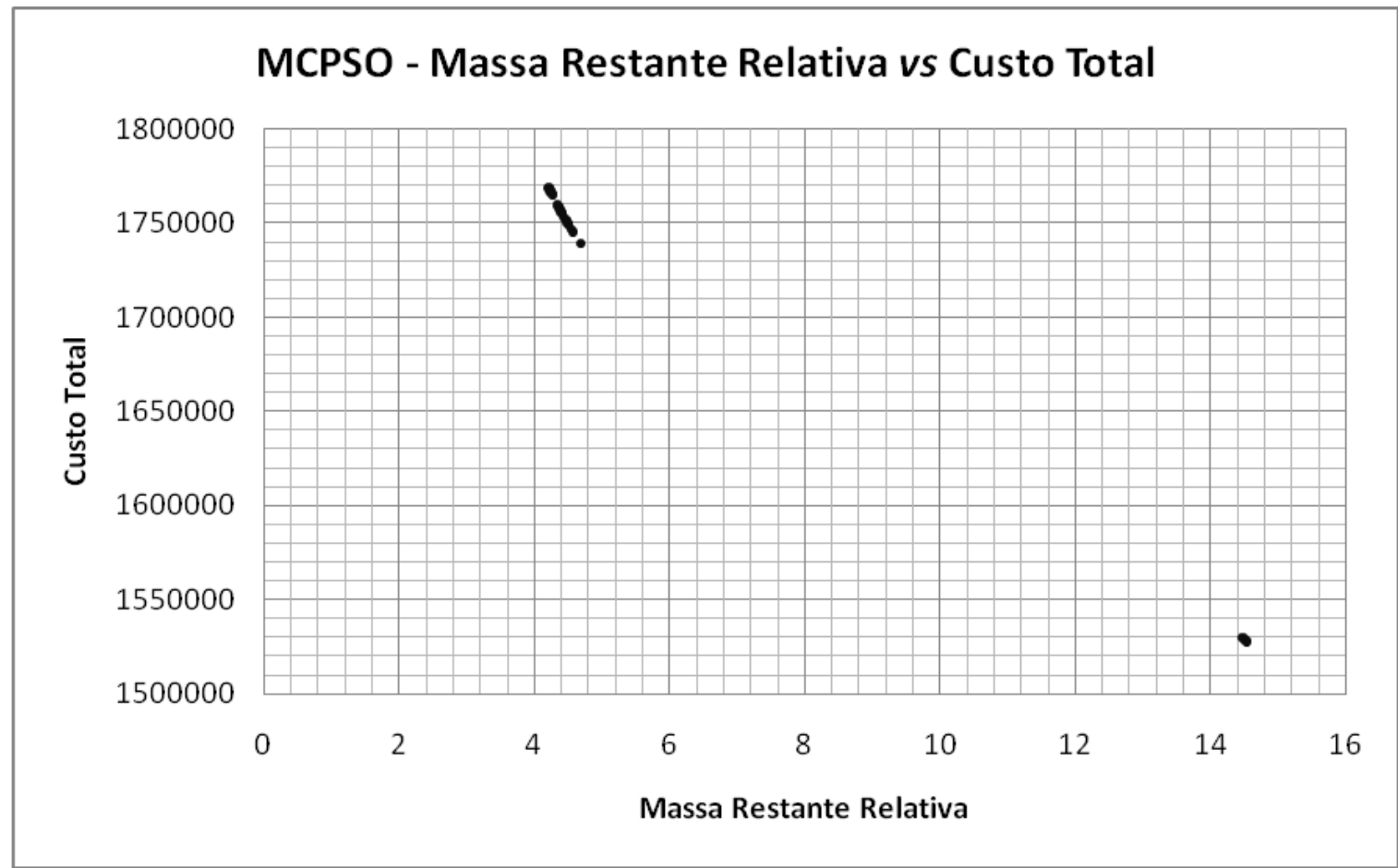

Figura 8 - Soluções encontradas pelo MCPSO com 100 voos

Figure 8 - Found solution with 100 flights of MCPSO

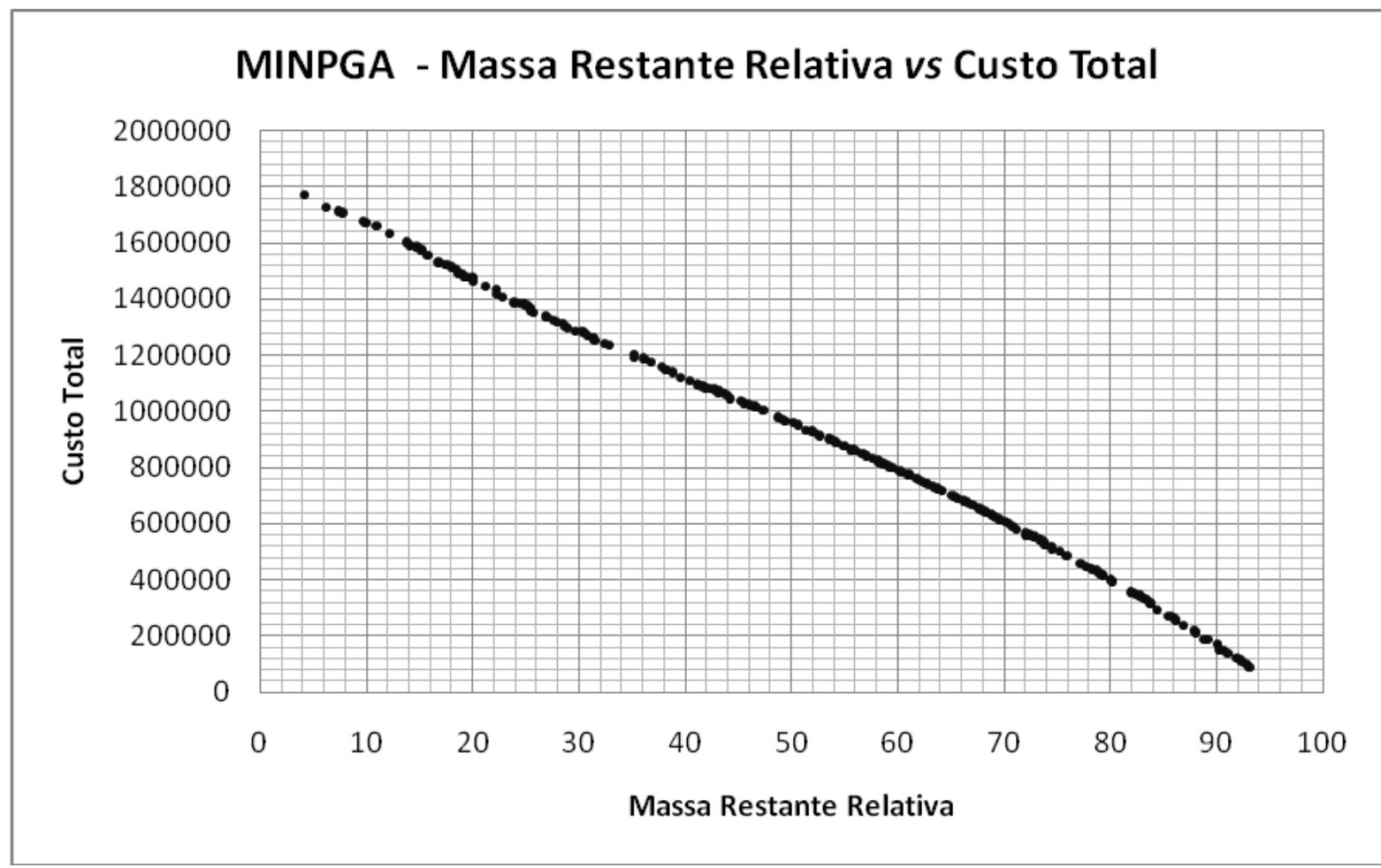

Figura 9 - Soluções encontradas pelo MINPGA com os parâmetros do quadro 3

Figure 9 - Found solutions with MINPGA parameters on square 3

\section{DISCUSSÃO E CONCLUSÕES}

Apresentou-se a solução de um problema de otimização multi-objetivo da remediação de água subterrânea em um sítio hipotético simples. A escolha de um sítio hipotético simples mostrouse apropriada, uma vez que o objetivo era mostrar as vantagens de se resolver o problema apresntado por meio de métodos evolucionários em duas modalidades relativamente novas: problemas multi-objetivo e algoritmos multi-população. 
Conforme é possível observar pela revisão bibliográfica procedida, o problema pode ser abordado por diversas técnicas, evidenciando a eficácia das técnicas evolucionárias, bem como a sua plasticidade. Ainda se pode enfatizar que, de maneira geral, os AE multi-população são mais eficientes do que os seus correlatos unipopulação, uma vez que o aumento da diversidade genética e a troca entre populações diferentes contribuem diretamente para a eficiência dos AE.

O uso de uma RNA em lugar de chamadas diretas ao MODFLOW e ao MT3DMS trouxe ganhos de velocidade de processamento de ordem exponencial. No entanto, como era esperado, houve uma pequena perda de informação tanto durante o processo de contaminação quanto após os poços iniciarem o bombeamento. Contudo, não se considera esse fator como desabonador da metodologia empregada, desde que as soluções pro- curadas por AE são sempre sub-ótimas, sendo, sem embargo, completamente aceitáveis como resultados de técnicas estocásticas.

Finalmente, mostrou-se que os AE multipopulação MINPGA e MCPSO constituem-se boas alternativas para solucionar problemas de otimização com dois objetivos conflitantes, como a minimizalção da pluma contaminante e a minização do custo de remediação sob a técnica bombear-e-tratar. $\mathrm{O}$ custo de remediação ótimo deve ser escolhido diretamente da frente de Pareto, observada a restrição sobre a quantidade final de contaminante desejado, considerando que o nível de remoção do contaminante no aquífero varia entre $4 \%$ e $15 \%$ utilizando-se o MCPSO; e de $4 \%$ até $96 \%$, utilizando-se o MINPGA. Para conseguir reduzir o contaminante presente para cerca de $4 \%$ de sua massa inicial, o custo mínimo estimado pelo MINPGA é de cerca de \$1.760.000,00.

\section{AGRADECIMENTOS}

O primeiro autor deste artigo é pesquisador apoiado pela Universidade de Fortaleza. O desenvolvimento deste artigo contou com o apoio logístico do Laboratório de Hidráulica Computacional (LAHC) - Pós-graduação do Departamento de Engenharia Hidráulica e Ambiental (POSDEHA)/Universidade Federal do Ceará (UFC). Agradecemos também ao analista de sistemas Wanialdo Lima pela ajuda na construção do código-fonte.

\section{REFERÊNCIAS}

AGUADO, E.; REMSON, I. PIKUL, M. F.; THOMAS, W. A. Optimum pumping for aquifer dewatering. Journal Hydraulics Division, ASCE, v. 100, p. 860-877, 1974.

AHLFELD, D.; MULVEY J.; PINDER, G.;WOOD, E. Contaminated Groundwater Remediation Design Using Simulation, Optimization, and Sensitivity Theory 1. Model Development, Water Resour. Res.; v. 24, n. 3, p. 431-441, 1988.

AHLFELD, D.P.; MULLIGAN, A.E. Optimal Management of flow in groundwater systems. Academic Press, California, p. 185, 2000.

BLANKS, W.; FLECK, W. Proceedings of the 26th Annual Water Resources Planning and Management Conference held in Tempe, Arizona, June, p. 6-9, 1999.

CARRANO, E.G.; WANNER, E.F.; TAKAHASHI, R.H.C. A Multicriteria Statistical Based Comparison Methodology for Evaluating Evolutionary Algorithms. IEEE Transactions on Evolutionary Computation, v. 15, n. 6, p. 848-870, dezembro, 2011.

CHANG, L.-C, HSIAO, C.-T. Dynamic optimal ground water remediation including fixed and operation costs. Ground Water, National Ground Water Association, v. 40, n. 5, p. 481-490, 2002.

DEMUTH H. and M. BEALE: Neural Network Toolbox: For Use with Matlab, The MathWorks Inc, Natick, USA, 2005.
DOUGHERTY, D. E. \& MARRYOTT, R. A. Optimal Groundwater Management. Simulated Annealing, Water Resour. Res. v. 27, n. 10, p. 2493-2508, 1991.

ERICKSON, Mark; MAYER, Alex; HORN, Jeffrey. Multiobjective optimal design of groundwater remediation systems: application of the Niched Pareto Genetic Algorithm (NPGA). Advances in Water Resources. v. 25, p. 51-65, 2002.

ESPINOZA, F. P.. A Self-Adaptive Hybrid Genetic Algorithm for Optimal Groundwater Remediation Design. Urbana, Illinois, USA,, 2003, 152 p. Tese (PhD). University of Illinois at Urbana-Champaign.

FOGEL, L.; OWENS, A.; WALSH, M. Artificial intelligence through simulated evolution. New York: John Wiley \& Sons, 1966.

GOMES C. C.; PINNTO M. R.; PEIXOTO, M. C. S. Métodos De Otimização Evolucionária Utilizados Na Remediação De Águas Subterrâneas: Uma Breve Descrição. In: IX SIMPÓSIO DE RECURSOS HÍDRICOS DO NORDESTE. ASSOCIAÇÃO BRASILEIRA DE RECURSOS HÍDRICOS - ABRH, 2008, v. único, p. .

GORELICK, S. M.; VOSS, C. I.; GILL, P. E.; MURRAY, W.; SAUNDERS, M. A.; WRIGHT, M. H. Aquifer reclamation design: The use of contaminant transport simulation combined with nonlinear programming. Water Resources Research, v. 20, n. 4, p. 415-427, 1984. 
GUAN, J. \& ARAL M. M. Optimal remediation with well locations and pumping rates selected as continuous decision variables. Journal of Hydrology, v. 221, p. 20-42, 1999.

HAGAN, M. T.; M. B. MENHAJ. Training feedforward networks with the Marquardt algorithm, IEEE Transactions on Neural Networks, v. 5, n. 6, p. 989-993, 1994.

HAYKIN, S. Neural Networks: a Comprehensive Foundation, 2 ed.; Prentice Hall, Upper Saddle River, USA, 1999.

HOLLAND, J. H. Adaptation in Natural and Artificial Systems: an introductory analysis with applications to biology, control, and artificial intelligence. Michigan: University of Michigan Press, Ann Arbor, 1975.

KARATZAS, G. P.; and PINDER, G. F. The solution of groundwater quality management problems with a nonconvex feasible region a cutting plane optimization technique. Water Resources Research, v. 32, n. 4, p. 1091-1100, 1996.

KOZA, J.R. Genetic Programming: On the Programming of Computers by Means of Natural Selection. Cambridge, MA: MIT Press, 1992.

LEFKOFF, L. J.; and GORELICK, S. M. (1986). Design and cost analysis of rapid aquifer restoration systems using flow simulation and quadratic programming. Ground Water, v. 24 , n. 6 , p. $777-790,1986$

LIANA JOHN. O Estado de São Paulo, 19 de fevereiro de 2003. Disponível no Site: <http://www.demet.ufmg.br/ milenioagua/P/MeioTextos.php>.

MCDONALD, M.G.; HARBAUGH, A.W.. A modular three-dimensional finite-difference ground-water flow model. Techniques of Water Resources Investigations Livro 06- Capítulo A1, 586p, United States Geological Survey, 1988.

MCKINNEY, D. C.; LIN, M. D. Approximate Mixed-Integer Nonlinear Programming Methods for Optimal Aquifer Remediation Design, Water Resour. Res. v. 31, n. 3, p. 731$740,1995$.

MORGAN, D. R.; EHEART, J. W. \& VALOCCHI, A. H. Aquifer remediation design under uncertainty using a new chance constrained programming technique. Water Resources Research, v. 29, n. 3, p. 551-562, 1993.
NEELAKANTAN, T. R.; PUNDARIKANTHAN, N. V. Hedging rule optimization for water supply reservoir system. Water Resources Management. v. 13, p. 409-426, 1999.

NIU, B.; ZHU, Y-L.; HE, X-X. A Multi-population Cooperative Particle Swarm Optimizer for Neural Network Training. Springer-Verlag, p. $570-576,2006$.

PINNTO, M.R. Algoritmos Evolucionários Multipopulação na Otimização Multiobjetivo da Remediação de Águas Subterrâneas. Fortaleza, Ceará, Brasil, 2009. 160 p. Dissertação (mestrado em Engenharia Civil - Recursos Hídricos). Universidade Federal do Ceará.

RAO, ZHENG FU, \& JAMIESON, D. G. The Use of Neural Networks and Genetic Algorithms for Design of Groundwater Remediation Schemes. Hydrology and Earth System Sciences, v. 1, p. 345 - 356, 1997.

RECHENBERG, I. Evolutions Strategie: Optimierung Technischer Systeme nach Prinzipien der Biologischen Evolution. Frommann-Holzboog, Stuttgart, 1973.

ROGERS, L. L. \& DOWLA, F. U. Optimization of groundwater remediation using artificial neural networks with parallel solute transport modeling. Water Resour. v. 30, n. 2, p. 457-481, 1994.

LETTENMAIER, D. P. \& WOOD, E. F. "Hydrologic Forecasting" in Handbook of Hydrology. Org. by Maidment, D. R., McGraw-Hill Inc., New York, USA, 26.1-26.30. 1993.

SINHA, E.; MINSKER, B. S. Multiscale Island Injection Genetic Algorithm for Ground Water Remediation. Advances in Water Resources, v. 30, n. 9, p. 1933-1942, 2007.

SIVANANDAM, S. N.; DEEPA, S. N. Introduction to Genetic Algorithms. Springer, 2008.

TOKOS, H.; PINTARIC, Z.N.; YANG, Y. Bi-Objective Optimization of a Water Network via Benchmarking. Journal of Cleaner Production, v. 39, p. 168-179, 2013.

ZHENG, C. MT3D: A modular three-dimensional transport model for simulation of advection, dispersion, and chemical reactions of contaminants in groundwater systems. Ada, OK: 1990. Report to the Kerr Environmental Research Laboratory, US Environmental Protection Agency. 